\title{
ENTRE ESQUERDAS RENOVADORAS E REFUNDADORAS: OS SISTEMAS PARTIDÁRIOS BRASILEIRO E VENEZUELANO NO CONTEXTO DA "MARÉ ROSA"
}

\author{
BETWEEN LEFTIST RENOVATORS AND REFOUNDERS: THE BRAZILIAN \\ AND VENEZUELAN PARTY SYSTEMS IN THE CONTEXT OF THE "PINK \\ TIDE"
}

\author{
Wanderley dos Reis Nascimento Júnior ${ }^{*}$ \\ PUC-Rio e UNILA, Foz do Iguaçu, PR
}

Resumo: $O$ artigo tem por objetivo analisar as características dos sistemas partidários brasileiro e venezuelano no contexto da "maré rosa". A conformação de diversos governos que se definem como esquerda ou centro-esquerda, progressistas de uma maneira geral, representou um momento ímpar para a historiografia política LatinoAmericana e fez emergir uma vasta literatura sobre as trajetórias e características destas forças políticas. Independentemente das categorizações utilizadas, as forças políticas que emergiram no Brasil e na Venezuela são inseridas, consensualmente, em categorias distintas. De modo mais amplo, lançamos mão da metodologia comparativa e, em sentido estrito, nos fundamentamos no diálogo com as unidades de análise de sistemas partidários (MAINWARING; TORCAL, 2006 e HUNTINGTON, 1968). Isto posto, defende-se que distintos sistemas partidários foram responsáveis pela conformação de diferentes tipologias de esquerdas.

PALAVRAS-CHAVES: Sistemas Partidários; Maré Rosa; América do Sul.

\section{ABSTRACT}

Abstract: The article aims to analyze the characteristics of the Brazilian and Venezuelan party systems in the context of the "Pink Tide". The conformation of several governments that define themselves as left or center-left progressives in general, represented a unique moment for the political history of Latin American and sprouted a vast literature on the paths and characteristics of these political forces. Regardless of used categorizations, the political forces that emerged in Brazil and Venezuela are inserted consensually in different categories. More broadly, we used the comparative methodology and, strictly speaking, we base on the dialogue with the units of analysis of party systems (MAINWARING; TORCAL, 2006 and HUNTINGTON, 1968). That said, it is argued that distinct party systems were responsible for forming different types of lefts.

Keywords: Party Systems; Tide Rose; South America.

\footnotetext{
* Doutorando em Relações Internacionais pelo Programa de Doutorado Interinstitucional (IRI/PUC RIO e UNILA). Mestre em Integração Contemporânea da América Latina pela Universidade Federal da Integração Latino-Americana. Bacharel em Relações Internacionais pela Pontifícia Universidade Católica de Goiás. Email: wjunioreis@gmail.com
} 
Wanderley dos Reis

Nascimento Júnior
Cadernos Prolam/USP, v.16, n.31, p.99-118, jul./dez.2017

DOI: 10.11606/issn.1676-6288.prolam.2017.134200

\section{INTRODUÇÃO}

O advento do século XXI apresentou para a historiografia política LatinoAmericana um fato sem precedentes: a ascensão de partidos e coalizões que se definem como esquerda ou centro-esquerda a governos nacionais em diversos países da região. Tal fato fez emergir uma vasta literatura visando explicar as trajetórias e características destas forças políticas.

O fator inédito deste acontecimento é corroborado por Roberts (2008, p. 86) ao afirmar que "Este giro político sin precedentes ha ubicado a casi dos tercios de la población latinoamericana bajo algún tipo de régimen de izquierda y ha hecho trizas el llamado 'Consenso de Washington' '.

Este fenômeno foi definido por Panizza (2006) como "maré rosa" e faz referência à ascensão de partidos de centro-esquerda na Europa em meados da década de 90. Apesar das especificidades distintas entre o caso europeu e o latino-americano, a expressão foi mantida e a variável "onda rosa" (Silva, 2011) também tem sido utilizada.

Neste período ocorre o empreendimento de diferentes experiências de governos "progressistas" em países como Argentina, Bolívia, Brasil, El Salvador, Chile, Equador, Nicarágua, Paraguai, Uruguai e Venezuela. À vista disto, autores como Panizza (2006), Castañeda (2006), Lanzaro (2008), Roberts (2008), Silva (2011), Levitsky e Roberts (2011) debateram suas trajetórias e apresentaram possíveis tipologias para o fenômeno.

Dessa forma, assim como demonstraram as características comuns que possibilitaram a ascensão destes movimentos ao poder central de seus países, estes autores apresentaram tipologias possíveis e apesar das divergências e convergências, constata-se, de maneira geral, a existência de dois grupos dentro destas esquerdas.

Panizza (2006), Castañeda (2006) e Lanzaro (2008) defendem a existência de uma esquerda "populista" e outra "socialdemocrata", já Silva (2011) apresenta que a tipificação de uma esquerda "populista" e outra "socialdemocrata" é polissêmica e acusatória, pois caracteriza, respectivamente, uma como boa e outra como má, portanto, defende a caracterização de um grupo de esquerdas "refundadoras" e outro de "renovadoras".

\footnotetext{
${ }^{1}$ Entendido como governos que buscam "mudanças/transformações”, em maior ou menor medida de acordo com o caso, em relação ao status quo anterior (SILVA, 2011).
} 
Isto posto, e considerando que segundo Silva (2011), inserem-se, por um lado, no grupo das esquerdas "refundadoras": o Partido Socialista Unido de Venezuela (PSUV)2, antes Movimiento Quinta República (MVR), na Venezuela; por outro, no grupo das esquerdas "renovadoras": o Partido dos Trabalhadores (PT), no Brasil, a questão que se impõe é: diferentes sistemas partidários foram responsáveis pela conformação de diferentes tipos de esquerdas?

A escolha recai sobre este objeto pelo fato de que, independentemente dos autores e quesitos adotados (PANIZZA 2006; LANZARO 2008; SILVA 2011) as forças progressistas destes dois Estados têm sido inseridas sempre em categorias distintas, isto nos permitirá verificar se o contexto político no qual elas traçaram suas trajetórias de ascensão ao poder central nacional foi responsável pelas características que as inserem em tipologias díspares.

Neste trabalho, de modo mais amplo, lançamos mão da metodologia comparativa, por entendermos que "a comparação, enquanto momento da atividade cognitiva, pode ser considerada como inerente ao processo de construção do conhecimento nas ciências sociais (SCHNEIDER; SCHIMITT, JOB, 1998, p. 49). Em sentido estrito, nos fundamentamos no diálogo com as unidades de análise propostas pela literatura especializada (MAINWARING; TORCAL, 2006 e HUNTINGTON, 1968) que detalhamos na seção inicial.

Salientamos que as tipologias apresentadas consideraram, de modo direto, apenas as características dos partidos e, somente de maneira transversal, dos sistemas partidários como um todo. Dessa forma, defende-se que não somente as características dos atores políticos, mas, necessariamente, dos sistemas partidários foram responsáveis pela conformação de diferentes tipologias de esquerdas.

O ineditismo da ascensão de diversas forças políticas consideradas como de esquerda ou centro-esquerda, progressistas de uma maneira geral, na maioria dos países da América Latina já seria fator justificável para a necessidade de compreensão deste fenômeno. Soma-se, ademais, a imprescindibilidade de entendimento da estrutura interna dos sistemas partidários e de seus atores, especificamente no âmbito do Mercado Comum do Sul (MERCOSUL), para, a partir daí, entender as potencialidades e limitações do bloco.

\footnotetext{
${ }^{2}$ Este trabalho não contemplou a análise do PSUV, como partido, pois sua criação ocorreu somente em 2006.
} 
Para isso, este trabalho está estruturado além desta introdução e das considerações finais em duas seções: a seção debutante apresenta o estado-da-arte da literatura especializada sobre as distintas forças de esquerdas do subcontinente e o debate sobre institucionalização de partidos e sistemas partidários; posteriormente, apresentamos uma comparação dos sistemas partidários, considerando as características institucionais do PT e do MVR e do conjunto no qual estes atores estavam inseridos no período anterior à chegada ao poder.

\section{ASPECTOS (DES)INSTITUCIONAIS DA MARÉ: UM MARCO TEÓRICO POSSÍVEL?}

O fenômeno de ascensão de forças progressistas na América Latina foi definido por Panizza (2006) como "maré rosa" e "onda rosa" por Silva (2011). Ambas as nomenclaturas fizeram referência à ascensão de partidos de centro-esquerda na Europa em meados da década de 90 e apesar das especificidades distintas de cada caso a expressão foi mantida no contexto latino-americano.

A manutenção da expressão "maré rosa" se dá, aparentemente, pelo mesmo fato do uso em voga da expressão "progressistas", pois, tendo em vista as análises já realizadas, o caráter ainda limitado das reformas empreendidas impossibilitaria a definição como "maré vermelha", assim, a opção pela nuance cor-de-rosa demonstra uma versão mais moderada do vermelho associado ao comunismo.

Neste trabalho adotaremos a expressão utilizada por Panizza (2006), sem prejuízo ao termo utilizado por Silva (2011). Esta escolha remonta ao entendimento semântico do termo, uma vez a expressão "maré" abrange um fenômeno mais amplo, enquanto a terminologia "onda" tende a significar um evento específico, como, por exemplo, "a 'quarta onda' de integração dos países latino-americanos"33 que está inserida dentro deste macrocontexto.

O período de elevação desta maré foi estudado por diversos autores, já mencionados anteriormente, que tipificaram as esquerdas de forma dicotômica. Assim, tendo em vista a tipologia proposta por Silva (2011) estamos diante de dois subgrupos de esquerdas, uma denominada "renovadora" e outra "refundadora".

\footnotetext{
${ }^{3}$ Ver SOUZA, Nilson Araújo. América Latina: as ondas da integração. In: Oikos (Rio de Janeiro), v. 11, n. 1, 2012, p. 87-126.
} 
Wanderley dos Reis Nascimento Júnior
Cadernos Prolam/USP, v.16, n.31, p.99-118, jul./dez.2017

DOI: 10.11606/issn.1676-6288.prolam.2017.134200

As primeiras são caracterizadas por um grau maior de institucionalização, maior integração ao sistema político, aceitação das instituições da democracia representativa [...] e pela crítica moderada ao neoliberalismo. As segundas são caracterizadas por um nível mais baixo de institucionalização, menor integração ao sistema político, pela integração crítica às instituições da democracia representativa e pela crítica radical ao neoliberalismo (SILVA, 2011, p. 254, itálico nosso).

Percebe-se que o critério de institucionalização refere-se, necessariamente, às forças políticas em si e não diretamente à estruturação do sistema partidário no qual estas estão inseridas.

Isto posto, inserem-se, segundo Silva (2011), no grupo das esquerdas "refundadoras": o Movimiento al Socialismo, na Bolívia (MAS); o Movimiento Alianza PAIS - Patria Altiva i Soberana (PAÍS), no Equador; e o Partido Socialista Unido de Venezuela (PSUV), antes Movimiento Quinta República (MVR), na Venezuela. No grupo das esquerdas "renovadoras": o Partido dos Trabalhadores (PT), no Brasil; o Partido Socialista de Chile (PSCh); a Frente Farabundo Martí para la Liberación Nacional (FMLN), em El Salvador; a Frente Sandinista de Liberación Nacional (FSLN), na Nicarágua; e a Frente Ampla (FA), no Uruguai.

Estas agremiações, portanto, encabeçaram governos em seus respectivos países e estão inseridas em um contexto mais amplo de grupos progressistas que têm o combate ao neoliberalismo ${ }^{4}$, em maior ou menor medida, como elemento comum. Portanto, emerge-se, conforme apresenta Sader (2013), um novo período considerado como pósneoliberal.

Independentemente das especificidades de cada caso, os governos formados por estas forças progressistas apresentam traços pós-neoliberais em comum, pois:

a) priorizam as políticas sociais e não o ajuste fiscal; b) priorizam os processos de integração regional e os intercâmbios Sul-Sul e não os tratados de livre-comércio com os Estados Unidos; c) priorizam o papel do Estado como indutor do crescimento econômico e da distribuição de renda, em vez do Estado mínimo e da centralidade do mercado (SADER, 2013, p. 138).

Uma das especificidades que deve ser melhor considerada e entendida, antes de caminhar-se em direção ao que a literatura especializada tem indicado como novo passo - avaliação das experiências destes governos - é, não somente as características destas agremiações que chegam ao poder, mas, necessariamente, o sistema partidário no qual estão inseridas.

\footnotetext{
${ }^{4}$ Entendido, de maneira geral, como "o projeto de realização máxima do capitalismo, na medida em que visa a mercantilização de todos os espaços das formações sociais” (SADER, 2013, p. 135).
} 
As categorizações propostas careceram, em maior ou menor medida, de análises dos sistemas partidários em si, pois se debruçaram, necessariamente, sobre os atores que constituem estes sistemas, ou seja, os partidos em si.

Assim, entendendo que o funcionamento da democracia sem a existência de partidos, mesmo que desejado por alguns, ainda não obteve propostas operacionalizáveis. Constata-se a necessidade de compreensão dos sistemas partidários e não apenas de seus elementos constituintes, uma vez que este entendimento nos auxiliará na compreensão do fenômeno da maré rosa.

Assim sendo, o sistema partidário entendido como "um conjunto de partidos que interagem de maneiras padronizadas" (MAINWARING; TORCAL, 2005, p. 252) ainda é o conjunto organizado no qual os articuladores da competição eleitoral buscam a objetivação de suas metas tornando o sistema político operativo.

Dessa forma, para caracterizar-se como tal, um sistema partidário deve ter: mais de dois partidos (SARTORI, 1976), alguma regularidade na distribuição do apoio eleitoral por partidos ao longo do tempo e alguma continuidade temporal destes elementos que o formam (MAINWARING; TORCAL, 2005), ou seja, este último aspecto se refere à institucionalização destas agremiações.

Portanto, a institucionalização supõe, inequivocamente, à sua continuidade tempo-espacial. Neste sentido, segundo Mainwaring e Torcal (2005, p. 254, itálico do autor),

Institucionalização refere-se a um processo pelo qual uma prática ou organização se torna bem estabelecida e amplamente conhecida, senão universalmente aceita. Os atores desenvolvem expectativas, orientações e comportamentos baseados na premissa de que essa prática ou organização prevalecerá no futuro previsível.

Assim, a institucionalização pode fazer referência ao sistema partidário como um todo, geralmente denominado "estruturação dos sistemas partidários", ou especificamente às organizações que constituem este conjunto, ou seja, a institucionalização dos partidos em si.

No leque de estudos da institucionalização do sistema partidário (SARTORI, 1982; ROSE e MACKIE, 1988; MAINWARING e SCULLY, 1995; MAINWARING, 2001 entre outros) destaca-se o trabalho de Mainwaring e Torcal (2005) no qual 
apresentam quatro dimensões da institucionalização do sistema partidário ${ }^{5}$ : a) nível de institucionalização dos partidos; b) grau de estabilidade nos padrões de competição entre os partidos - "volatilidade eleitoral"; c) grau de enraizamento dos partidos na sociedade; d) o grau de legitimidade dos partidos junto aos eleitores.

No âmbito teórico da institucionalização dos partidos (PANEBIANCO, 1988; LEVITSKY, 2003), o trabalho de Huntington (1968) é um referente e apresenta que:

O nível de institucionalização de qualquer sistema político pode ser definido pela capacidade de adaptação, complexidade, autonomia e coerência. Se estes critérios podem ser identificados e medidos, os sistemas políticos podem ser comparados em termos de seus níveis de institucionalização. E também será possível medir os aumentos e reduções na institucionalização das organizações e procedimentos específicos dentro de um sistema político ${ }^{7}$ (HUNTINGTON, 1968, p. 12, tradução e itálico nosso).

Logo, adotamos estes estudos como referentes, isto implica dizer que não nos propomos a operacionalizar, estritamente, tais conceitos. Esta escolha metodológica funda-se, primeiramente, na crítica apresentada pelos trabalhos recente de Braga (2010) e Tarouco (2010) que fundamentam-se na operacionalização destas unidades de análises, uma vez que o grau de estabilidade nos padrões de competição entre os partidos é facilmente mensurados pela volatilidade eleitoral, não pode-se dizer o mesmo quanto as demais unidades de análises.

Soma-se a isto a não aplicabilidade das capacidades propostas por Huntington (1968) - adaptação, complexidade, autonomia e coerência - em agremiações como, por exemplo, o caso do MVR que não atende a concepção de partido ${ }^{8}$, ainda que legalmente o fora.

\footnotetext{
5 A ordem das dimensões apresentadas no original foi alterada neste trabalho para contemplar nossas escolhas metodológicas, pois nos propomos a analisar tanto os aspectos institucionais do PT e do MVR, quanto o sistema partidário no qual estão inseridos (brasileiro e venezuelano). A primeira dimensão apresentada neste trabalho - institucionalização dos partidos - é, na verdade, a última apresentada pelos autores.

${ }^{6}$ Volatilidade eleitoral refere-se à transferência agregada de votos de um partido para os outros, de uma eleição para a próxima (PEDERSEN, 1983; PRZEWORSKI, 1975; ROBERTS e WIBBEL, 1999 apud MAINWARING; TORCAL, 2006).

7 "Institutionalization is the process by which organizations and procedures acquire value and stability. The level of institutionalization of any political sistem can be defined by the adaptability, complexity, autonomy and coherence. If these criteria can be identified and measures, political systems can be compared in terms of their levels of institutionalization. And it will also be possible to measure increases and decreases in the institutionalization of the particular organizations and procedures within a political system."

${ }^{8}$ Entendidos como "una institución, con una organización que pretende ser duradera y estable, que busca explícitamente influir en el Estado, generalmente tratando de ubicar a sus representantes
} 
Destarte, na seção seguinte daremos atenção à apresentar as características dos sistemas partidários brasileiro e venezuelano tendo como referente de análise as características apresentadas por Mainwaring e Torcal (2005) e, inseridos dentro desta perspectiva, a análise das forças políticas tendo como referente às categorias apresentadas por Huntington (1968). Dessa forma, tomamos esta teorização apenas como instrumentos didáticos a fim de vislumbrarmos as diferenças e similitudes entre os casos.

\section{DO BIPARTIDARISMO AO MULTIPARTIDARISMO: DOIS}

\section{CAMINHOS DISTINTOS}

Comparar sistemas partidários tão dispares muitas vezes não nos permite fazer constatações assertivas, no entanto, é de suma importante para delinear as diferenças existentes entre ambos contextos políticos.

Retomando as considerações feitas anteriormente, apresentamos, nas linhas que se seguem, uma comparação tendo como referente os seguintes aspectos: a) nível de institucionalização dos partidos; b) grau de estabilidade nos padrões de competição entre os partidos; c) grau de enraizamento dos partidos na sociedade; d) o grau de legitimidade dos partidos junto aos eleitores (MAINWARING; TORCAL, 2006).

A fim de sanar as dúvidas inerentes ao aspecto do grau de institucionalização dos partidos, apresentamos a trajetória dos partidos que chegaram aos Executivos nacionais no Brasil e Venezuela adotando uma apresentação que não se propõe a ser cronológica, mas que toma como referente às unidades de análise propostas por Huntington (1968) no que se refere às capacidades de adaptação, complexidade, autonomia e coerência.

\section{a. Brasil - PT}

Ao nascer das demandas da sociedade e não de decisões da elite governante brasileira, o PT destoa-se da tradição dos demais partidos do país. Neste sentido, esta agremiação cuja sua formação oficial remonta à fevereiro de 1980, constituiu-se a partir tipo de sustento popular" (ABAL MEDINA, 2002, p. 38). 
da junção de movimentos sociais, operários, intelectuais, exilados políticos e por setores da Igreja. (ANGELO; VILLA, 2009).

A característica peculiar de formação do PT dava ao partido um caráter "movimentista" o que, segundo o critério de "complexidade", o caracterizava como carente de institucionalização, pois esta complexidade envolve "a multiplicação das subunidades organizacionais, hierárquica e funcionalmente, e diferenciação de tipos separados de subunidades organizacionais" (HUNTINGTON, 1968, p. 18, tradução nossa).

Entretanto, as inovações institucionais foram introduzidas ao longo dos anos, assim, o partido

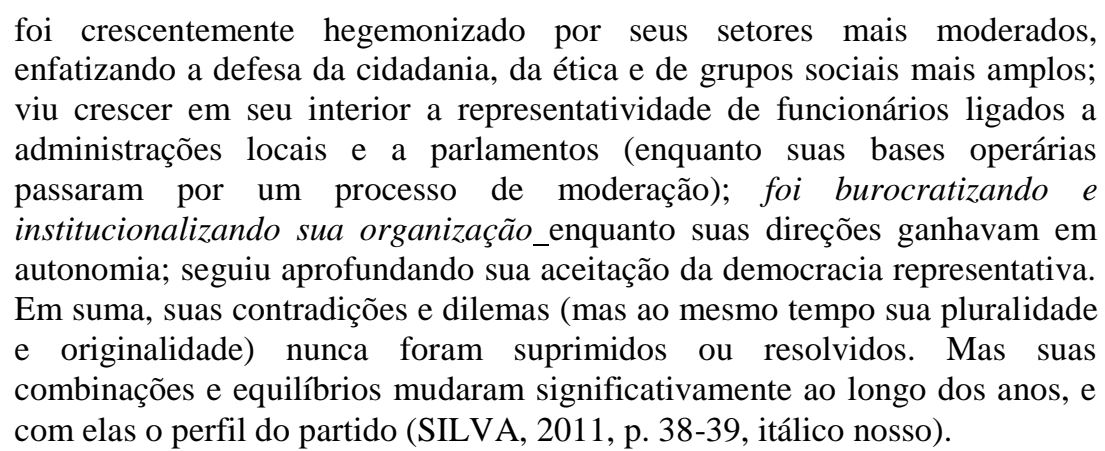

Esta institucionalização através da complexidade é um aspecto sob o qual o PT inovou ao demarcar bem sua característica até então sui generis para o ambiente brasileiro por se caracterizar como um partido de tendências institucionalizadas, ou seja, pelo reconhecimento plural do partido de forma legal (SAMUELS, 2004).

A progressão da institucionalidade através da capacidade de "complexidade" do PT, implicou, também, a gradativa contemplação da capacidade de "coerência", ao se considerar que "quanto mais unificada e coerente é uma organização, mais institucionalizada ela é; quanto maior a desunião da organização, menos institucionalizada ela é." "HUNTINGTON, 1968, p. 22, tradução nossa).

O alcance da capacidade de "coerência" se deu, entre outros aspectos, em consequência da institucionalização das tendências, pois, a partir daí "a figura do ‘filiado' é a única reconhecida pelas normas legais do partido, deixando de lado a noção

\footnotetext{
9 "multiplication of organizational subunits, hierarchically and functionally, and differentiation of separate types of organizational subunits."

10 "The more unified and coherent an organization is, the more highly institutionalized it is; the greater the disunity of the organization, the less it is institutionalized."
} 
de 'militante'." (SILVA, 2011, p. 72). Neste sentido, o partido é visto como um todo no qual convergem múltiplos setores.

A manutenção desta "coerência" deveu-se, no caso petista, à "autonomia" já que “em um sistema político altamente desenvolvido, organizações políticas tem uma integridade que lhes falta em sistemas menos desenvolvidos""11 (HUNTINGTON, 1968, p. 20, tradução nossa), esta integridade refere-se a construção de procedimentos que não tornem estas organizações tão vulneráveis à influências externas.

No caso petista, uma característica que representa sua capacidade de "autonomia" é

a implantação de mecanismos internos de democracia direta como plebiscitos, referendos, prévias eleitorais e consultas às bases. A mais importante delas é sem dúvida a eleição direta das direções em todos os níveis, com voto de todos os filiados (que legalmente possuem o mesmo peso, independentemente do seu grau e forma de atuação), e que refletiu e reforçou transformações significativas do partido, como veremos adiante (SILVA, 2011, p. 62).

Por fim, como última capacidade institucional elencamos a de "adaptabilidade" que, segundo Huntington (1968, p. 13) "é uma característica organizacional adquirida. Dá-se, em sentido bruto, em função do ambiente desafiador e da idade". ${ }^{12}$

Esta capacidade aparentemente é a principal responsável pelo crescimento eleitoral que culminou na chegada do PT à Presidência da República, pois o PT soube adaptar-se na medida que muitas de suas "tendências" abraçaram a democracia representativa de forma estratégica e o partido como um todo.

Soma-se a isto sua gradativa progressão rumo ao centro do espectro político, entretanto Silva (2011, p. 56) defende que,

Trata-se de um processo muito mais complexo que uma mera expansão ou caminhada ao centro do espectro partidário: tal dimensão, que esteve presente, explica pouco acerca da estratégia vitoriosa desses partidos. Tratase, de maneira geral, de um longo processo de adaptação à modernidade latino-americana, e à sua etapa atual em particular - na medida em que as referidas transformações regionais dizem respeito a ambos os níveis.

Percebe-se que o aspecto adaptativo do partido foi de suma importância para sua chegada ao poder no Brasil, uma vez que essa adaptação não foi somente no sentido de

\footnotetext{
11 "In a highly developed political system, political organizations have an integrity which they lack in less developed systems."

12 "is an acquired organizational characteristic. It is, in a rough sense, a function of environmental challenge and age."
} 
angariar mais votos, como, também, de entendimento das transformações inerentes à práxis social.

\title{
b. Venezuela - MVR
}

Assim como as origens do PSUV remontam ao MVR, as deste último podem ser buscadas no Movimento Bolivariano Revolucionário 200 (MBR-200), organização militar secreta sob a qual Hugo Chávez tentou um golpe em 1992 (LÓPEZ MAYA, 2008).

Após a fracassada tentativa de golpe popularizou Chávez e possibilitou uma aproximação ainda maior entre o MBR e a população civil, esta gradativa correlação de forças propiciou a criação do MVR que poderia abarcar este elemento de sustentação popular. Assim,

\begin{abstract}
En la campaña electoral de 1998 el MBR 200 creó el MVR como estrutura electoral que le permitiría, sin contaminar su vida interna, establecer alianzas con grupos y organizaciones de signo ideológico diverso, que deseaban apoyar la candidatura de Chávez [...] A diferencia del MBR 200, el MVR era una estructura electoral vertical y centralizada, al servicio de la candidatura de Chávez, sin espacios de debate, ni pretensiones de formar ideológicamente a sus miembros. Su heterogeneidad era mayor a la del MBR 200, facilitando uma gestión donde el componente personal de la autoridad se fue haciendo determinante (LÓPEZ MAYA, 2008, p. 58).
\end{abstract}

Desta maneira, evidencia-se o caráter fluido do movimento que se apresenta como partido no sentido legalista do termo, no qual não há espaços de debate e tampouco a formação política-ideológica de seus membros o que materializa seu caráter "movimentista".

Neste sentido, não há dissenso na literatura especializada e segundo Silva (2011, p. 201): "montou-se então um partido inserido na legislação vigente relativa a esse tipo de organização, ainda que, na prática, uma parte das regras que regiam sua vida interna tenha se tornado 'letra morta'.".

Deste modo, torna-se impossível e inadequado a construção de uma análise que se paute nas unidades de análises de partidos políticos, uma vez que o MVR não atende minimamente aos critérios de complexidade, coerência, autonomia e, em certa medida, de adaptação no sentido proposto por Huntington (1968).

Entretanto, deve-se considerar, principalmente, o contexto ao analisar o MVR, pois o "partido" conseguiu chegar ao poder sem a necessidade de desenvolver um 
processo de moderação e adaptação, isto deu-se, em grande parte, devido a crise do sistema partidário que será apresentada na seção seguinte.

De maneira geral, é necessário considerar que, como percebemos, o PT surge como um partido considerado "movimentista", mas que se institucionaliza ao longo dos anos que coincidiram com sua ascensão à Presidência da República; por outro lado, no caso venezuelano, não ocorreu o mesmo e o nível de análise de institucionalização dos partidos não pôde sequer ser aplicado, pois o MVR se caracterizou, apenas como um arranjo partidário para a chegada de Hugo Chavez à presidência.

Isto posto, considera-se que pode haver partidos mais institucionalizados e menos institucionalizado em sistemas partidários mais fluidos ou cristalizados, portanto, faz-se necessário compreender o conjunto no qual estes atores políticos estão inseridos.

O sistema partidário venezuelano alcançou seu ápice de institucionalização durante o período de 1973 a 1993 no qual os partidos Acción Democratica (AD) e Comité de Organización Política Electoral Independiente (COPEI) dominavam a cena política, fator diretamente ligado ao Pacto de Puntofijo ${ }^{13}$. Assim, segundo MOLINA (2011, p. 12): “La volatilidad electoral se reduce sensiblemente y alcanza: 12\% entre las elecciones de 1973 y 1978, 13\% entre 1978 y 1983, y 10\% entre 1983 y 1988."

Entretanto, o derrocamento econômico impulsionado pela queda do valor do petróleo se transforma em uma aguda crise política que expressou-se eleitoralmente, segundo Molina (2001, p. 12) “ [en el] fin del sistema de bipartidismo atenuado, no polarizado e institucionalizado e instauraron un sistema de partidos que puede caracterizarse como de pluralismo polarizado y des-institucionalizado."

O sistema partidário caminhou-se, portanto, em direção ao colapso de sua estrutura bipartidarista e constitui-se como multipartidário, no qual as agremiações tradicionais perderam espaço para setores de centro e, gradativamente, de extrema esquerda representado especificamente pelo $M V R$.

Esta ruptura com o bipartidarismo representou uma gradativa desinstitucionalização do sistema partidário indicada pela característica de estabilidade

\footnotetext{
13 Pacto firmado pelas principais forças políticas (AD e COPEI) em 1958 sob o qual estas se comprometiam a competir dentro das regas do jogo democrático, a entrar em um governo de coalização qualquer que seja o resultado eleitora e a gerir a administração pública com base em um programa acordado. O Partido Comunista da Venezuela foi excluído do acordo. (MOLINA, 2001)
} 
eleitoral percebe-se que a volatilidade eleitoral aumentou significativamente: $32 \%$ no período 1988-1993, 41\% em 1993-1998 e 32\% em 1998-2000 (MOLINA, 2001).

O caso brasileiro, à exemplo do venezuelano, também saiu de uma sistema bipartidário, constituído sob a ditadura militar, e caminhou em direção à um sistema multipartidário. Entretanto os rumos traçados pela Venezuela em comparação com o Brasil foram, em essência, claramente distintos.

Por tratar-se do período ditatorial brasileiro nos vemos impossibilitados de traçar os dados comparativos com o período bipartidarista venezuelano. Entretanto, é necessário considerar que o sistema partidário brasileiro atual, segundo Braga (2010, p. $50)$,

\begin{abstract}
originou-se em 1982, portanto, em pleno processo de transição do regime político. Naquele momento, cinco partidos participaram do primeiro pleito, o qual inauguraria o retorno ao pluripartidarismo: PMDB, PDS, PDT, PTB e PT. No entanto, embora a reforma partidária de 1979 tivesse como objetivo desmantelar o bipartidarismo vigente durante o regime militar, manteve-o até meados da década de 1980 .
\end{abstract}

Neste sentido, o sistema partidário, ao contrário do caso Venezuela, no período prévio à ascensão de Lula caracterizou-se por uma crescente estabilidade tomando como referente o índice de volatilidade eleitoral: 16,8\% no período de 1990-1994, 12,9\% entre 1994-1998, e 15,3\% em 1998-2002 (BRAGA, 2010).

Percebe-se uma queda significativa da volatilidade do sistema, considera-se o um aumento no período de 1998-2002, pois é justamente na eleição de 2002 que ocorre a alternância no Executivo nacional, entretanto, a modo de consideração, nos indica Braga (2010) que no período subsequente 2002-2006 o valor caiu à 10,3\%.

Desta forma, a modo geral de compreensão vislumbramos a Tabela 1 indicando o índice de volatilidade dos sistemas partidários brasileiro e venezuelano.

Tabela 1 - Índice de volatilidade eleitoral média na Venezuela e no Brasil

\begin{tabular}{|c|c|c|}
\hline País & $\begin{array}{c}\text { Volatilidade eleitoral média, } \\
\text { câmara baixa }\end{array}$ & $\begin{array}{c}\text { Eleições incluídas para } \\
\text { volatilidade }\end{array}$ \\
\hline Brasil & 24,1 & $1986-2002$ \\
\hline Venezuela & 31,3 & $1978-2001$ \\
\hline
\end{tabular}

Fonte: Elaboração própria com base nos dados de Mainwaring e Torcal (2005).

À vista disso, percebemos que a capacidade de mensuração do índice de volatilidade eleitoral nos permite uma visão mais ampla do sistema como um todo ao entender que no caso venezuelano têm-se, a priori, uma estabilidade com índice baixo de volatilidade eleitoral - 10\% entre 1983-1988 (MOLINA, 2001) - e a ruptura do 
sistema bipartidarista influi numa crescente volatilidade; por outro lado, no caso brasileiro, o surgimento de um sistema multipartidário com progressiva redução da volatilidade eleitora.

Entretanto, ao adentramos as duas últimas dimensões consideradas por Mainwaring e Torcal (2005) - grau de enraizamento dos partidos na sociedade legitimidade dos partidos junto aos eleitores - temos um problema de nexo causal, no qual os dados apresentados, não confluem, necessariamente, para uma indicação assertiva.

Inicialmente, lançamos mão dos dados disponíveis sobre a confiança dos eleitores (Tabela 2), em seus respectivos países, nos partidos políticos e percebemos que os dados confrontados entre os dois países indicam para um panorama basicamente similar e, de certo modo, na contramão da categorização proposta por Mainwaring e Torcal (2005), pois a gradual institucionalização do sistema partidário brasileiro, considerada a redução da volatilidade eleitora, não impactou diretamente no grau de confiança nos partidos políticos.

Tabela 2 - Confiança nos Partidos Políticos - Brasil/Venezuela (1995-2002)*

\begin{tabular}{|c|c|c|c|c|c|c|c|c|c|c|c|c|c|c|c|c|}
\hline ANO & \multicolumn{2}{|c|}{1995} & \multicolumn{2}{|c|}{1996} & \multicolumn{2}{|c|}{1997} & \multicolumn{2}{|c|}{1998} & \multicolumn{2}{|c|}{2000} & 2001 & \multicolumn{2}{|c|}{2002} & Média & Média \\
\hline PAís & BR & VE & BR & VE & BR & VE & BR & VE & BR & VE & BR & VE & BR & VE & BR & VE \\
\hline Muita & $5 \%$ & $6 \%$ & $1 \%$ & $3 \%$ & $5 \%$ & $7 \%$ & $4 \%$ & $5 \%$ & $2 \%$ & $9 \%$ & $6 \%$ & $11 \%$ & $3 \%$ & $7 \%$ & $4 \%$ & $7 \%$ \\
\hline Alguma & $12 \%$ & $10 \%$ & $15 \%$ & $8 \%$ & $13 \%$ & $14 \%$ & $16 \%$ & $10 \%$ & $10 \%$ & $14 \%$ & $14 \%$ & $20 \%$ & $10 \%$ & $12 \%$ & $13 \%$ & $13 \%$ \\
\hline Pouca & $32 \%$ & $28 \%$ & $32 \%$ & $23 \%$ & $38 \%$ & $32 \%$ & $40 \%$ & $27 \%$ & $29 \%$ & $24 \%$ & $38 \%$ & $29 \%$ & $28 \%$ & $26 \%$ & $34 \%$ & $27 \%$ \\
\hline Nenhuma & $48 \%$ & $54 \%$ & $51 \%$ & $64 \%$ & $42 \%$ & $45 \%$ & $39 \%$ & $57 \%$ & $56 \%$ & $49 \%$ & $39 \%$ & $39 \%$ & $56 \%$ & $51 \%$ & $47 \%$ & $51 \%$ \\
\hline $\begin{array}{c}\text { Não } \\
\text { respondeu }\end{array}$ & $0 \%$ & $1 \%$ & $0 \%$ & $1 \%$ & $1 \%$ & $1 \%$ & $1 \%$ & $0 \%$ & $2 \%$ & $1 \%$ & $1 \%$ & $1 \%$ & $1 \%$ & $2 \%$ & $1 \%$ & $1 \%$ \\
\hline Não sabe & $2 \%$ & $1 \%$ & $0 \%$ & $1 \%$ & $1 \%$ & $1 \%$ & $1 \%$ & $0 \%$ & $1 \%$ & $2 \%$ & $2 \%$ & $1 \%$ & $2 \%$ & $2 \%$ & $1 \%$ & $1 \%$ \\
\hline
\end{tabular}

Fonte: Elaboração própria com base nos dados do Latinobarometro (2015).

* Os dados do ano de 1999 não estavam disponíveis.

Assim, os dados demonstram que, na Venezuela, os que tinham muita e alguma confiança nos partidos cresceram nos anos 1998 a 2001 (5 e 10\% à 11 e 20\%, respetivamente) o que pode indicar o aumento da confiança em algum "partido" especificamente em detrimento à outros, como por exemplo no MVR, pois este período compreende o dos primeiros anos de governo de Hugo Chavez.

Neste sentido, Tarouco (2010) corrobora esta asserção - considerando que a ordem de apresentação das unidades de análises foi alterada em nosso trabalho - ao afirmar que 
Wanderley dos Reis Nascimento Júnior
Cadernos Prolam/USP, v.16, n.31, p.99-118, jul./dez.2017 DOI: 10.11606/issn.1676-6288.prolam.2017.134200

a unidade de análise a que se refere o conceito, apenas a primeira dimensão (regularidade dos padrões de competição) diz respeito ao conjunto dos partidos. As demais três dimensões (raízes na sociedade, legitimidade diante dos atores políticos e independência das organizações) são atributos de partidos individuais, que podem variar de um partido para outro dentro do mesmo sistema partidário e inclusive no mesmo partido ao longo do tempo (TAROUCO, 2010, p. 177-78).

Entretanto, isto não retira valor à teorização que, assim como os demais trabalhos sociais, não se propõe a ser estática e universal. Assim, Molina (2001) nos apresenta esta limitação ao debruçar-se sobre o caso venezuelano e concluir que:

La compenetración social de los partidos tradicionales, otrora en un nivel considerado como asfixiante por diversos analistas, tiende a derrumbarse aunque con mayor lentitud que su caudal electoral. Surgen nuevas organizaciones sociales autónomas, que reclaman independencia de los partidos políticos y, al mismo tiempo, hay una erosión significativa de las lealtades partidarias (desalineación) sin que se haya producido una realineación en torno a los nuevos partidos (MOLINA, 2001, p. 17).

Apesar das implicações de possibilidade de mensuração, avançamos no sentido de permitir um entendimento geral, partindo, assim, para a unidade de análise do grau de legitimidade dos partidos "considerando-os uma parte necessária da política democrática, mesmo quando criticam determinados partidos e manifestam ceticismo em relação aos partidos em geral (TORCAL, GUNTHER e MONTERO, 2002 apud MAINWARING; TORCAL, 2006).

Quando nos referimos à legitimidade dos partidos fazemos alusão à importância que os eleitores conferem à estas instituições como instrumento operacionalizantes do sistema político e, por conseguinte, responsáveis por processar as demandas da população em um ambiente democrático.

Assim, temos, nos dados (Tabela 3) a indicação de que o sistema partidário venezuelano, no período anterior à ascensão do MVR, demonstrava índices de rejeição aos partidos políticos relativamente altos escalando de 37\%, em 1995, a 49\%, em 2000.

Tabela 3 - Legitimidade dos partidos - Brasil e Venezuela (1995-2002)*

\begin{tabular}{|l|c|c|c|c|c|c|c|c|c|c|c|c|}
\hline \multicolumn{1}{|c|}{ ANO } & \multicolumn{2}{|c|}{1995} & \multicolumn{2}{c|}{1997} & \multicolumn{2}{c|}{2000} & \multicolumn{2}{c|}{2001} & \multicolumn{2}{c|}{2002} & Média & Média \\
\hline \multicolumn{1}{|c|}{ PAís } & BR & VE & BR & VE & BR & VE & BR & VE & BR & VE & BR & VE \\
\hline $\begin{array}{l}\text { Sem partidos políticos não pode } \\
\text { haver democracia }\end{array}$ & $47 \%$ & $55 \%$ & $50 \%$ & $50 \%$ & $50 \%$ & $38 \%$ & $42 \%$ & $44 \%$ & $46 \%$ & $55 \%$ & $47 \%$ & $48 \%$ \\
\hline $\begin{array}{l}\text { A democracia pode funcionar } \\
\text { sem partidos }\end{array}$ & $42 \%$ & $37 \%$ & $38 \%$ & $42 \%$ & $36 \%$ & $49 \%$ & $40 \%$ & $46 \%$ & $32 \%$ & $35 \%$ & $38 \%$ & $42 \%$ \\
\hline Não respondeu & $0 \%$ & $1 \%$ & $1 \%$ & $3 \%$ & $12 \%$ & $10 \%$ & $2 \%$ & $4 \%$ & $2 \%$ & $5 \%$ & $3 \%$ & $5 \%$ \\
\hline
\end{tabular}


Fonte: Elaboração própria com base nos dados do Latinobarometro (2015).

* Os dados referentes aos anos de 1996, 1998 e 1999 não estavam disponíveis.

É interessante agregar que esta depreciação com relação aos partidos fora, na Venezuela, promovido pelo próprio MVR, conforme nos apresenta Silva (2011, p. 201).

O próprio Chávez desenvolveu, na campanha de 1998, um discurso antipartidos (e anti-institucional de maneira geral). O lançamento do PSUV no final de 2006 foi mais uma tentativa, feita "de cima para baixo", de dotar o processo político de um núcleo partidário mais estruturado e de massas, após algumas iniciativas infrutíferas no sentido de institucionalizar e democratizar o MVR.

Esta estratégia "antipartidarista" está inserida no contexto mais amplo de crise do sistema partidário em si, no qual, o objetivo final é a não assimilação do movimento com os "partidos tradicionais".

O caso brasileiro apesar de apresentar números relativamente similares ao venezuelano, quando nos debruçamos sobre os dados percebemos um leve decréscimo no percentual de eleitores que acreditam que a democracia pode funcionar sem partidos de $42 \%$ em 1995 a $32 \%$ em 2002, diferentemente do caso venezuelano, no Brasil não houve, necessariamente, uma campanha de antipartidos.

No entanto, entende-se que não somente a opinião dos eleitores importam, como, também, os fatos, como, por exemplo, ao distanciamento por parte dos próprios partidos de seus elementos institucionais para a sua suplantação por características personalistas.

Aí demarca-se a diferença, nesta unidade de análise, entre Venezuela e Brasil. A primeira vê a emersão de um aspecto personalista mais arraigado, isto é demonstrado por Molina (2001, p. 17)

Un signo de ellos es la creciente personalización de la política en torno a liderazgos nacionales y regionales. Esta personalización ha sido consecuencia de: a) la descomposición de las lealtades hacia los partidos tradicionales causada por sus errores, por la corrupción, por su incapacidad para afrontar satisfactoriamente la crisis económica, y por la atenuación de la confrontación ideológica luego del desenlace de la guerra fría; b) la reforma institucional venezolana que estableció la elección directa de gobernadores y alcaldes, porque propició una nueva vía para el surgimiento de líderes políticos regionales y nacionales, distinta a la burocracia interna de los partidos.

Pode-se entender que a própria crise do sistema partidário venezuelano fora responsável pela gradativa (des) legitimidade dos partidos junto à sociedade que foi deixando de ser visto como instrumentos de sustentação democrática. . 


\section{CONSIDERAÇÕES FINAIS}

Enfim, pôde-se perceber que, apesar de haver limitações quanto à operacionalização de conceitos, estes são de extrema utilidade no sentido de entendimento mais amplo dos contextos políticos, entendidos como conjuntos não estáticos, mas em constante construção.

Isto considerado, vislumbramos que as forças políticas que ascenderam aos Executivos nacionais no Brasil e na Venezuela possuem trajetórias e características essencialmente distintas, esta constatação já havia sido proferida por estudiosos que se debruçaram sobre o fenômeno da "maré rosa". Somam-se a este fator, as características dos sistemas partidários no qual estavam inseridas estas forças políticas. Aqui reside o aporte principal deste trabalho, considerando que as categorizações que foram construídas sobre a "maré rosa" versaram, em grande medida, sobre a institucionalização das agremiações e não, necessariamente, do sistema partidário.

Assim, corroboramos as constatações de que se, por um lado, o PT nasce como um partido com características "movimentistas", este foi se institucionalizando ao longo da sua trajetória em direção ao poder central nacional; por outro lado, o MVR que têm suas origens em um grupo militar, mantém-se, essencialmente, fluido, não atendendo a critérios mínimos de institucionalização.

Adiciona-se a isto, as demais características dos sistemas partidários. Tanto o sistema partidário brasileiro, quanto o venezuelano, deixaram o bipartidarismo como elemento característico e caminharam rumo ao multipartidarismo, ainda que as nuances de cada percurso demonstrem ser, essencialmente, distintas.

Tem-se o sistema, antes bipartidário, venezuelano em profunda crise o que implicou no crescimento do índice de volatilidade eleitoral; decréscimo do grau de enraizamento dos partidos, de maneira geral, e da legitimidade destes junto à sociedade.

Já no caso brasileiro, percebe-se uma cristalização do sistema partidário com indicadores de gradativa diminuição da volatilidade eleitoral que não se vê diretamente refletida no grau de enraizamento dos partidos, mas, de certa maneira, representou um crescimento sutil da legitimidade destas agremiações junto à população.

Portanto, entendemos que as características tão diferentes dos sistemas partidários brasileiro e venezuelano influenciaram diretamente na conformação de 
diferentes forças progressistas, principalmente no que se refere à necessidade (possibilidade) de moderação do discurso.

No caso venezuelano, a característica não institucionalizada do MVR é demonstrada não apenas por seus rearranjos internos, mas, fundamentalmente, pelo contexto de ruptura do sistema partidário que permitiu a existência desta organização sem institucionalizar-se e a sustentação de um discurso antisistêmico. No caso brasileiro, percebemos que a progressiva institucionalização do sistema partidário refletiu no âmbito interno do PT e isto representou a manutenção de um discurso mais moderado.

Finalmente, podemos falar em esquerdas "renovadoras" e "refundadoras" aferindo que uma de suas características destoantes são as diferenças marcantes entre seus sistemas partidários, principalmente, no que se refere ao seu grau de institucionalização.

\section{REFERÊNCIAS}

ABAL MEDINA, Juan Manuel Abal. Elementos teóricos para el análisis contemporáneo de los partidos políticos: un reordenamiento del campo semántico. In: M. Cavarozzi, J. M. A. Medina (comps.). El asedio a la política. Los partidos latinoamericanos en la era neoliberal, Rosário: Homo Sapiens, 2002. Disponível em: <http://www.catedras.fsoc.uba.ar/castiglioni/doc6.pdf> Acesso em: 20 nov. 2015.

ANGELO, Vitor Amorim; VILLA, Marco Antonio. O Partido dos Trabalhadores e a política brasileira (1980-2006): uma história revisitada. São Carlos: Editora EdUFSCar, $1^{a}$ ed., 2009.

BOBBIO, Norberto. Direita e esquerda: razões e significados de uma distinção política / Norberto Bobbio; tradução Marco Aurélio Nogueira - São Paulo: Editora da Universidade Estadual Paulista, 1995.

BRAGA, Maria do Socorro Sousa. Eleições e Democracia no Brasil: a caminho de partidos e sistema partidário institucionalizados. Revista Brasileira de Ciência Política. $\mathrm{N}^{\circ} 04,2010$.

CASTAÑEDA, Jorge. Latin America's Left Turn. Foreign Affairs, New York, 2006.

GIDDENS, Anthony. Para além da esquerda e da direita. São Paulo: Editora da Universidade Estadual Paulista, 1996. 
HUNTINGTON, Samuel. Political order in changing societies. New Haven: Yale University Press, 1968.

LANZARO, Jorge. La social democracia criolla, Nueva Sociedad 217, 2008. Disponível em < http://www.nuso.org/upload/articulos/3546_1.pdf> Acesso em: 10 out. 2015.

La "tercera ola" de las izquierdas latinoamericanas: entre el populismo y la social democracia, en Las izquierdas latinoamericanas y el gobierno: experiencias y desafíos. Madrid: Pablo Iglesias, 2006.

LEVITSKY, Steven. Transforming labor-based parties in Latin América: Argentine peronism in comparative perspective. Cambridge: Cambridge University Press, 2003.

; ROBERTS, Kenneth (Ed.). Latin America's "Left Turn": A Framework for Analysis. In: LEVITSKY, Steven; ROBERTS, Kenneth (Ed.) The Resurgence of the Latin American Left. Baltimore: Johns Hopkins, 2011.

LÓPEZ MAYA, Margarita. Venezuela: Hugo Chávez y el bolivarianismo. Revista Venezolana de Economía y Ciencias Sociales, v. 14, n. 3, 2008.

MAINWARING, Scott P. Sistemas partidários em novas democracias: o caso do Brasil. Porto Alegre: Mercado Aberto; Rio de Janeiro: Editora FGV, 2001.

; SCULLY, Timothy R. (orgs.) Building democratic institutions: party systems in Latin America. Stanford: Stanford University Press, 1995.

MAINWARING, Scott; TORCAL, Mariano. Teoria e institucionalização dos sistemas partidários após a terceira onda de democratização. Opin. Publica, Campinas , v. 11, n. 2, p. 249-286, Oct. 2005 Disponível em: <http://www.scielo.br/scielo.php?script=sci_arttext\&pid=S0104-

62762005000200001\&lng=en\&nrm=iso>. Acesso em: 17 Nov. 2015.

MILL, John Stuart. Sistema de Lógica Dedutiva e Indutiva. São Paulo: Abril Cultural (Coleção Os Pensadores), 1974.

MOLINA, José E. EL SISTEMA DE PARTIDOS VENEZOLANO: De la partidocracia al personalismo y la inestabilidad. La des-institucionalización y sus consecuencias. 2001. Disponível em: <http://lasa.international.pitt.edu/lasa2001/molinajose.pdf> Acesso em 20 nov. 2015.

PANEBIANCO, Angelo. Political parties: organization and power. Cambridge: Cambridge University Press, 1988.

PANIZZA. Francisco. La marea rosa. In: Análise de Conjuntura OPSA, nº 8 . Instituto Universitário de Pesquisas do Rio de Janeiro: Rio de Janeiro, 2006.

PRZEWORSK, Adam; TEUNE, Henry. The logic of comparative social inquiry. Michigan: Wiley-Interscience, 1970

RIGGIROZZI, Pia; TUSSIE, Diana. The Rise of Post-Hegemonic Regionalism. The Case of Latin America. New York: United Nations University Series on Regionalism, Vol. 4, 2012, XVII. 
RÍOS, Sandra; VEIGA, Pedro da Motta P. O regionalismo pós-liberal, na América do Sul: origens, iniciativas e dilemas. SANTIAGO: CEPAL, 2007. Disponível em: $<$ http://repositorio.cepal.org/bitstream/handle/11362/4428/S2007612_pt.pdf?sequence= $1>$

ROBERTS, Kenneth. ¿Es posible una social democracia en América Latina?, Nueva Sociedad 217, 2008.. Disponível em: http://132.248.9.34/hevila/Nuevasociedad/2008/no217/7.pdf

ROSE, Richard \& MACKIE, Thomas. Do parties persit or fail? The big trade-off facing organizations. In: LAWSON, Kay \& MERKL, Peter (eds.). When parties fail. Princeton: Princeton University Press, 1988.

SADER, Emir. A construção da hegemonia pós-neoliberal. In: SADER, Emir (Org.). 10 anos de governos pós-neoliberais no Brasil: Lula e Dilma. Rio de Janeiro: Boitempo; São Paulo: FLACSO, 2013. p. 135-44.

SAMUELS, David. From socialism to social democracy: party organization and the transformation of the Workers' Party in Brazil. Comparative Political Studies, v. 37, n. 9, 2004.

SANAHUJA, José Antonio. La construcción de una región: Suramérica y el regionalismo posliberal. In: Una región en construcción: Unasur y la integración en América del Sur. Cienfuegos, Manuel y José Antonio Sanahuja (eds.) Barcelona: CIDOB, 2010, pp. 87-134. Disponível em: http://www.cidob.org/ca/content/download/23373/271703/file/28_Interrogar_UNAREG IONENCONSTRUCCION.pdf

SARTORI, Giovanni. Partidos e sistemas partidários. Brasília: UNB, 1982.

Parties and party systems: a framework for analysis. New York: Cambridge University Press, 1976.

SCHNEIDER, Sergio; SCHIMITT, JOB, Claudia. O uso do método comparativo as Ciências Sociais. Cadernos de Sociologia, Porto Alegre, v. 9, p. 49-87, 1998.

SERBIN, Andrés. Regionalismo y soberanía nacional en América Latina: los nuevos desafíos. In Documentos CRIES, No 15, Buenos Aires: CRIES, 2010. Disponível em: <http://www.cries.org/wp-content/uploads/2010/09/Documentos-15-web.pdf>

SILVA, Fabricio Pereira da. Vitórias na Crise: Trajetórias das esquerdas latinoamericanas contemporâneas. Ponteio, Rio de Janeiro, 2011.

SINGER, André. A segunda alma do partido dos trabalhadores. Novos estud. CEBRAP [online]. 2010, n.88, pp. 89-111. ISSN 0101-3300.

SOARES DE LIMA, Maria Regina; COUTINHO, Marcelo. Integração Moderna. Análise de Conjuntura OPSA, Rio de Janeiro, n. 1, 2006, p. 1-15, jan. Disponível em: <http://www.plataformademocratica.org/Publicacoes/22207.pdf> Acesso em: 22 ago. 2015. 
Wanderley dos Reis

Nascimento Júnior
Cadernos Prolam/USP, v.16, n.31, p.99-118, jul./dez.2017 DOI: 10.11606/issn.1676-6288.prolam.2017.134200

TAROUCO, Gabriela. Institucionalização partidária no Brasil (1982-2006). Revista Brasileira de Ciência Política, $n^{\circ}$ 04, 2010.

Recebido em 30/06/2017.

Aceito em 09/11/2017.

Publicado em 02/04/2018. 